\title{
TP53 single nucleotide polymorphism (rs1042522) in Iranian patients with coronary artery disease
}

\author{
VERSA OMRANI-NAVA ${ }^{1}$, AKBAR HEDAYATIZADEH-OMRAN ${ }^{1}$, REZA ALIZADEH-NAVAEI ${ }^{1}$, \\ VAHID MOKHBERI ${ }^{2}$, ROZITA JALALIAN ${ }^{2}$, GHASEM JANBABAEI ${ }^{1}$, OMOLBANIN AMJADI ${ }^{1}$, \\ GHASEM RAHMATPOUR $^{1}$ and AMIR MOZAFFARI ${ }^{1}$
}

${ }^{1}$ Gastrointestinal Cancer Research Center, Mazandaran University of Medical Sciences, Sari, Mazandaran 48166-33131;
${ }^{2}$ Cardiovascular Research Center, Mazandaran University of Medical Sciences, Sari, Mazandaran 48471-91971, Iran

Received March 2, 2018; Accepted June 22, 2018

DOI: $10.3892 /$ br.2018.1121

\begin{abstract}
Chronic diseases including coronary artery disease (CAD) impose a high burden in terms of mortality and disability particularly in developing countries. Both genetic and environmental risk factors confer susceptibility to CAD. Meanwhile, a functional polymorphism in the tumor protein p53 (TP53) gene (codon 72, exon 4) has been reported to be associated with a wide range of cancers and inflammatory disorders. There are controversies regarding CAD and involvement of the TP53 codon 72 single nucleotide polymorphism; therefore, the present case-control study was conducted to evaluate the potential association between this TP53 polymorphism and CAD in an Iranian population. A total of 153 subjects (including 70 patients diagnosed with CAD and 83 subjects with normal coronary parameters, determined by angiography) were genotyped for the TP53 (rs1042522) polymorphism by the polymerase chain reaction-restriction fragment length polymorphism technique. Clinical and laboratory findings were also evaluated. The $\chi^{2}$ test and unpaired Student's t-test were applied to compare genotype and allele distributions and clinical characteristics between the two groups. Significant associations of the Pro72 allele [odds ratio $(\mathrm{OR})=1.66, \mathrm{P}=0.027$ ] and Pro/Pro genotype $(\mathrm{OR}=2.91, \mathrm{P}=0.022)$ with $\mathrm{CAD}$ were identified. No associations between patients' clinical findings and genotypes were apparent. Therefore, according to present findings, the TP53 Pro72 allele may be involved in the development of CAD along with conventional risk factors in patients from Northern Iran.
\end{abstract}

Correspondence to: Dr Akbar Hedayatizadeh-Omran, Gastrointestinal Cancer Research Center, Mazandaran University of Medical Sciences, 70 Razi Street, Sari, Mazandaran 48166-33131, Iran E-mail: akbar_hedayati@yahoo.com

Key words: coronary artery disease, polymerase chain reaction, restriction fragment length polymorphism, tumor suppressor protein p53

\section{Introduction}

Coronary artery disease (CAD) is the leading cause of mortality worldwide (1). CAD is a chronic inflammatory condition that poses major health challenges to developing countries (2,3). Technological advances and industrialization, as well as appropriate access to health services, have shifted global morbidity and mortality patterns from infectious to non-communicable diseases $(4,5)$. Therefore, as a result of this epidemiological transition, cardiovascular disorders (CVDs), cancers, diabetes and other chronic conditions are considered among the main causes of disability and mortality worldwide $(6,7)$. According to World Health Organization statistics in 2014, CVDs including CAD accounted for approximately half of all fatalities in the Iranian population (8). Similar to the majority of pathological and geographical specific conditions including cancer (9), CAD is affected by the interaction between ethnicity and environmental and genetic factors. Obesity, type 2 diabetes, high blood pressure, dyslipidemia as well as smoking and alcohol consumption are among the main risk factors (10-12) The genetic aspect of this disease is also notable, as genome-wide association studies have led to the identification of multiple genetic variants involved in atherosclerotic processes (13).

Tumor protein p53 (TP53) is among the known genes associated with a broad range of diseases (14-17). The protein encoded by the TP53 gene is a transcription factor involved in programmed cell death (apoptosis), cell cycle regulation, proliferation and DNA repair, and thus serves as a crucial tumor suppressor $(18,19)$. Different types of TP53 gene alteration have been associated with a variety of cancers including myelodysplastic syndromes (20) and gastrointestinal cancers (21), and metabolic diseases including type 2 diabetes mellitus and obesity $(15,22)$. TP53 mutations may increase cellular expansion, loss of apoptosis and genetic instability $(23,24)$. In this regard, a single nucleotide polymorphism (SNP) on codon 72 of TP53 (rs1042522), which encodes proline (CCC) or arginine (CGC), appears to be associated not only with the risk of certain malignant (e.g., cancers of the breast and gastrointestinal system) $(25,26)$ and chronic diseases (e.g., diabetic nephropathy) $(15,27)$ but also with patient survival and treatment response $(28,29)$. The functional 
characteristics of these two varieties are distinct, which may influence the ability of the final protein to induce inflammation or apoptosis (30). When considering the role of TP53 in the regulation of cell growth, proliferation and inflammatory processes, previous studies have identified inconclusive results in patients with CAD (31-33). Therefore, the present study aimed at assessing the TP53 codon 72 SNP in CAD patients in Northern Iran.

\section{Materials and methods}

Study subjects. In the present case-control study, TP53 codon 72 polymorphism was determined by polymerase chain reaction (PCR)-restriction fragment length polymorphism (PCR-RFLP) in CAD and non-CAD subjects. The patients were selected among those attending Fatimah Zahra Heart Hospital (Sari, Iran) who underwent standard coronary angiography [via the Judkins method (34)] by two cardiologists between December 2016 and September 2017. The case group (CAD patients; $n=70$ ) included patients characterized by coronary artery stenosis (at least $50 \%$ diameter stenosis in one or more vessels) and the control group consisted of subjects with normal cardiac catheterization results (non-CAD $n=83$ ). Demographic and clinical information including age, sex, body mass index (BMI), laboratory and clinical findings were obtained from the medical records of participants. Patients with systemic infections, inflammatory diseases and/or cancer were excluded. The study protocol was approved by the Ethics Committee of Mazandaran University of Medical Sciences, Sari, Iran (approval no. IR.MAZUMS.REC.96.2817) and informed consent was obtained from all subjects.

By considering $\alpha=0.05$ and $80 \%$ statistical power $(\beta=0.20)$, the sample size of the present study was calculated based on the results of Khan et al (35), which reported the proportion of the Arg/Arg genotype in the case group as 28\% and in the control group as $9 \%$.

TP53 genotyping analysis. Fasting venous blood samples $(3 \mathrm{ml})$ were taken in EDTA tubes and frozen at $-20^{\circ} \mathrm{C}$ until subsequent analysis.

Genomic DNA was extracted by a modified salting-out method using an EXTRA-GENEI kit (BAGHealth Care GmbH, Lich, Germany), according to the manufacturer's protocol, and the quality of DNA was determined using a spectrophotometer (WPA Biowave II; Biochrom, Ltd., Cambridge, UK) Determination of TP53 genotype for Arg/Pro polymorphism was performed according to a protocol reported by Ara et al (36). The primers 5'-TTGCCGTCCCAAGCAATGGATGA-3' and 5'-TCTGGGAAGGGACAGAAGATGAC-3' were used to amplify exon 4 (containing codon 72) of the TP53 gene. In each PCR reaction tube, $1 \mu \mathrm{l}$ each of forward and reverse primers, 2-3 $\mu$ l genomic DNA, $10 \mu$ l MasterMix (Parstous Biotechnology, Mashhad, Iran) and diethyl pyrocarbonate-treated water up to $20 \mu \mathrm{l}$ were added. The amplification cycle consisted of an initial denaturation and enzyme activation $\left(94^{\circ} \mathrm{C}, 5 \mathrm{~min}\right)$, denaturation $\left(94^{\circ} \mathrm{C}, 30 \mathrm{sec}\right)$, annealing $\left(63^{\circ} \mathrm{C}, 30 \mathrm{sec}\right)$, extension $\left(72^{\circ} \mathrm{C}, 5 \mathrm{~min}\right)$ followed by a final extension $\left(72^{\circ} \mathrm{C}, 5 \mathrm{~min}\right)$. The products were enzymatically digested by $1 \mu \mathrm{l} \mathrm{BstUI}(10 \mathrm{U} / \mu \mathrm{l})$ restriction endonuclease (Fermentas; Thermo Fisher Scientific, Inc., Waltham, MA, USA), which cleaves in the middle of 5'-CGCG-3' sequences. The products were then electrophoresed in 3\% agarose gel containing DNA staining dye (Green Viewer ${ }^{\mathrm{TM}}$; Parstous Biotechnology) and visualized by ultraviolet light using a transilluminator device (UVIdoc-HD6; Uvitec, Ltd., Cambridge, UK). The proline allele presents as a single band at $199 \mathrm{bp}$. The arginine allele cuts into two fragments of 86 and 113 bp. Accordingly, Pro/Pro subjects exhibit a 199 bp band, Arg/Arg exhibit 86 and 113 bands, and heterozygote subjects exhibit all three bands (17).

Statistical analysis. Data analysis was conducted using GraphPad Prism version 5.0 (GraphPad Software, Inc., La Jolla, CA, USA). Categorical data are presented as number (percentage) and quantitative data are summarized as the mean \pm standard error of the mean. The $\chi^{2}$ test and unpaired Student's t-test were used to compare the frequency distribution of TP53 genotypes and quantitative data including laboratory and demographic variables between CAD patients and controls. Additionally, the distribution of TP53 Arg72Pro in CAD patients and normal subjects was assessed by $\chi^{2}$ test. The association between this SNP and CAD was determined by calculating odds ratios (ORs) and 95\% confidence intervals (95\% CIs) (37). The significance level was considered to be $\alpha=0.05$ and $\mathrm{P}<0.05$ was considered to indicate a statistically significant difference.

\section{Results}

Evaluation of demographic and clinical characteristics of study subjects. In the current study, a population of 153 subjects was evaluated for TP53 Arg72Pro SNP, comprising 70 CAD patients and 83 normal control subjects. The CAD group consisted of 42 males and 28 females with a mean age of $58.6 \pm 1.08$ (range, 39-84), and the control group included 45 males and 38 females with a mean age of $51.5 \pm 1.42$ (range, 31-72). As presented in Table I, there was a significant difference between the mean age of CAD patients and that of the controls $(\mathrm{P}<0.001)$. However, no differences were observed between the two groups in terms of sex distribution. Among the CAD cases, single vessel disease was the most frequent form of stenosis $(n=30)$, followed by three-vessel $(n=26)$ and two-vessel stenosis ( $\mathrm{n}=14$; data not shown). Among different clinical risk factors for $\mathrm{CAD}$, the prevalence of type 2 diabetes mellitus was identified to be significantly higher in patients (44.3 vs. $16.9 \%, \mathrm{P}<0.001$ ). Similarly, the prevalence of hypertension (HTN) and smoking was greater in the CAD group (50.0 vs. $32.5 \%, \mathrm{P}=0.028$; and 24.3 vs. $10.8 \%, \mathrm{P}=0.027$ ). No difference in the presence of dyslipidemia was identified between the two groups. CAD patients exhibited lower left ventricular ejection fraction (LVEF compared with the controls ( $48.25 \pm 1.06$ vs. $51.19 \pm 0.66 \%, \mathrm{P}=0.017$; Table I).

PCR and RFLP results. TP53 gene codon 72 encodes either arginine (CGC, Arg72) or proline (CCC, Pro72). Accordingly, three genotypes are expected: CC (Pro/Pro), GG (Arg/Arg) and GC (Arg/Pro) (38). Expectedly, PCR amplification with the specified primers resulted in the production of a 199-bp fragment. By adding BstUI restriction enzyme and in the presence of the proline allele, the fragment was not cleaved; while the arginine allele was converted into two smaller fragments 
Table I. Demographic and clinical characteristics of study subjects.

\begin{tabular}{lccc}
\hline Variable & Patients $(\mathrm{n}=70)$ & Controls $(\mathrm{n}=83)$ & P-value \\
\hline Age, years & $58.6 \pm 1.08$ & $51.5 \pm 1.42$ & $<0.001$ \\
Sex, male:female & $42: 28$ & $45: 38$ & 0.47 \\
Smokers & $17(24.3)$ & $9(10.8)$ & 0.027 \\
Diabetes & $31(44.3)$ & $14(16.9)$ & $<0.001$ \\
Hypertension & $35(50.0)$ & $27(32.5)$ & 0.028 \\
Dyslipidemia & $18(25.7)$ & $27(32.5)$ & 0.35 \\
Body mass index, $\mathrm{kg} / \mathrm{m}^{2}$ & $28.7 \pm 0.63$ & $28.7 \pm 0.80$ & 0.94 \\
Fasting blood sugar, $\mathrm{mg} / \mathrm{dl}$ & $135.6 \pm 8.00$ & $118.1 \pm 7.46$ & 0.10 \\
Total cholesterol, $\mathrm{mg} / \mathrm{dl}$ & $163.6 \pm 5.02$ & $158.3 \pm 3.82$ & 0.39 \\
Systolic BP, mmHg & $124.5 \pm 3.00$ & $125.7 \pm 2.96$ & 0.77 \\
Diastolic BP, mmHg & $79.3 \pm 1.11$ & $80.3 \pm 0.78$ & 0.45 \\
Left ventricular ejection fraction, $\%$ & $48.3 \pm 1.06$ & $51.2 \pm 0.66$ & 0.017 \\
\hline
\end{tabular}

Data are presented as mean \pm standard error of the mean or number (percentage). BP, blood pressure.

Table II. TP53 genotype frequency in CAD and control subjects.

\begin{tabular}{|c|c|c|c|c|}
\hline \multirow[b]{2}{*}{ TP53 codon 72 genotypes } & \multicolumn{2}{|c|}{ Frequency, n (\%) } & \multirow{2}{*}{$\begin{array}{c}\text { Odds ratio } \\
\text { (95\% confidence interval) }\end{array}$} & \multirow[b]{2}{*}{ P-value } \\
\hline & CAD & Control & & \\
\hline Arginine homozygote (Arg/Arg) & $17(24.3)$ & $27(32.5)$ & $1^{\mathrm{a}}$ & - \\
\hline Proline homozygote (Pro/Pro) & $22(31.4)$ & $12(14.5)$ & $2.91(1.15-7.37)$ & 0.022 \\
\hline Heterozygote & $31(44.3)$ & $44(53.0)$ & $1.11(0.52-2.39)$ & 0.77 \\
\hline
\end{tabular}

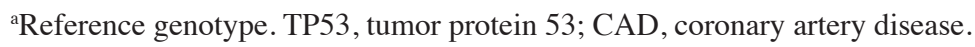

Table III. Arg/Pro allele frequency among CAD and control subjects.

\begin{tabular}{|c|c|c|c|c|}
\hline \multirow[b]{2}{*}{ Allele } & \multicolumn{2}{|c|}{ Frequency, n (\%) } & \multirow{2}{*}{$\begin{array}{l}\text { Odds ratio } \\
\text { (95\% confidence interval) }\end{array}$} & \multirow[b]{2}{*}{ P-value } \\
\hline & CAD & Controls & & \\
\hline Pro & 75 (53.6) & $68(41.0)$ & $1.66(1.05-2.61)$ & \\
\hline Arg & $65(46.4)$ & $98(59.0)$ & & 0.027 \\
\hline Total & $140(100.0)$ & $166(100.0)$ & & \\
\hline
\end{tabular}

CAD, coronary artery disease.

of 86 and $113 \mathrm{bp}$. Arg/Pro genotype was identified by all three fragments (Fig. 1).

The TP53 Arg72Pro genotype and allele distributions in the CAD patient and control groups are presented in Tables II and III. Based on the $\chi^{2}$ test, a significant difference was observed in the frequency of the Pro/Pro genotype between the two groups, with the genotype appearing more prevalent in the CAD group [odds ratio $(\mathrm{OR})=2.91, \mathrm{P}=0.022$; Table II] Accordingly, the Pro allele also appeared more frequent in the CAD group $(\mathrm{OR}=1.66, \mathrm{P}=0.027$; Table III). There were no apparent associations between genotype and HTN, diabetes, number of involved vessels or patients' sex (Table IV).

\section{Discussion}

Given that CAD is a major contributor to disability and mortality worldwide, identifying risk factors and adopting screening methods is expected reduce the health burden of the disease (1). Risk factors including changes in community structure and industrialization, sedentary lifestyle and increased rates of smoking, diabetes mellitus, dyslipidemia and hypertension have contributed to the establishment of $\mathrm{CAD}$ as one of the most common non-communicable diseases and causes of mortality (39-41). Along with the environmental risk factors mentioned, genetic background may also affect the 
Table IV. Association between clinical characteristics of coronary artery disease patients and TP53 Arg/Pro genotypes.

\begin{tabular}{|c|c|c|c|c|c|c|c|c|c|}
\hline \multirow[b]{2}{*}{ TP53 genotype } & \multicolumn{2}{|c|}{ Sex } & \multicolumn{2}{|c|}{ Hypertension } & \multicolumn{2}{|c|}{$\begin{array}{c}\text { Type } 2 \\
\text { diabetes mellitus }\end{array}$} & \multicolumn{3}{|c|}{$\begin{array}{l}\text { Number of coronary } \\
\text { arteries involved }\end{array}$} \\
\hline & Male & Female & Yes & No & Yes & No & $3 \mathrm{VD}$ & $2 \mathrm{VD}$ & $1 \mathrm{VD}$ \\
\hline Arg/Arg & 12 & 5 & 6 & 11 & 5 & 12 & 4 & 5 & 8 \\
\hline Pro/Pro & 12 & 10 & 11 & 11 & 11 & 11 & 9 & 5 & 8 \\
\hline Arg/Pro & 18 & 13 & 18 & 13 & 15 & 16 & 13 & 4 & 14 \\
\hline P-value & \multicolumn{2}{|c|}{0.57} & \multicolumn{2}{|c|}{0.32} & \multicolumn{2}{|c|}{0.36} & \multicolumn{3}{|c|}{0.54} \\
\hline
\end{tabular}

TP53, tumor protein 53; VD, vessel disease.

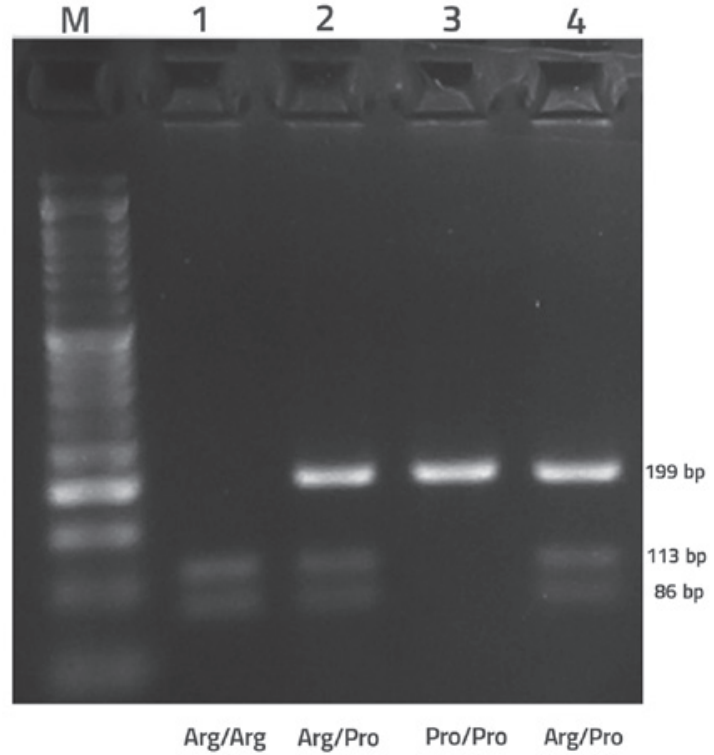

Figure 1. PCR-restriction fragment length polymorphism analysis of tumor protein p53 codon 72 single nucleotide polymorphism by $3 \%$ agarose gel electrophoresis. Shown are PCR products following digestion: Lane 1, Arg/Arg (GG); lanes 2 and 4, Arg/Pro (GC); lane 3, Pro/Pro (CC); lane M, 50 bp DNA size marker. PCR, polymerase chain reaction.

probability of developing CAD $(42,43)$. In this regard, genetic polymorphisms of the TP53 gene have been studied in CAD; however the results have so far been inconclusive $(31,35,44)$. As a key tumor suppressor gene, the main function of TP53 is to protect the genome from damage. Therefore, both its expression and polymorphisms have become topics of interest in cancer studies (45). The pathogenesis of cancer is a complex process, due to the accumulation and interactions of mutations in genes that control the cell cycle and apoptosis. TP53 gene is considered to serve an essential role in genetic predisposition to cancer, as it regulates DNA replication and repair, and cellular death; indeed mutated alleles of TP53 have been reported frequently in many human cancers (45-48). A common SNP of TP53 located on codon 72 encodes two alleles with distinct functional properties via transversion mutation (49). The arginine allele exhibits a greater apoptotic function than proline, which itself appears to be associated more with inflammation and activation of transcription (30). The Arg72Pro functional polymorphism of TP53 has been widely assessed in cancer susceptibility studies that have yielded contradictory results. In Iran, investigations on this SNP in primary open angle glaucoma (50) and breast (25) and colorectal (21) cancers have indicated associations with disease risk, but no evidence of association has been identified in gastric $(51,52)$ and head and neck (53) cancer, oral squamous cell carcinoma (54) and also hepatitis $\mathrm{C}$ infection (55).

It should be noted that cancer and CVDs share multiple biological characteristics (50). First, common risk factors for CVDs including levels of physical activity, alcohol and tobacco consumption, and comorbidity with diabetes and/or obesity are also commonly observed in cancers (56); and second, chronic inflammation is considered as an underlying factor for both diseases $(57,58)$. In the present study, the distribution of TP53 Arg72Pro genotypes between patients with CAD and control subjects was significantly different, and the proline allele was indicated to be associated with CAD risk. Gloria-Bottini et al (59) reported that CAD patients carrying the Pro allele (whether Pro/Pro or Arg/Pro) had significantly lower LVEF than those with Arg/Arg. This negative impact may be due to inflammatory characteristics of the proline allele. The joint presence of an active genotype of acid phosphatase locus 1 (carrying $* \mathrm{~B} / * \mathrm{C}$ alleles: $\mathrm{C} / \mathrm{T}$ in codon 43 and $\mathrm{C} / \mathrm{C}$ in codon 41) and TP53 Pro/Pro has been reported to increase the risk of CAD (32). In ulcerative colitis, a type of inflammatory bowel disease in which cytokines and inflammatory mediators including tumor necrosis factor- $\alpha$ and interleukin- 6 , and arachidonic acid metabolites including prostaglandin E2 and leukotriene B4 are involved (60), the presence of the proline homozygous genotype (Pro/Pro) significantly increased the disease duration ( $>7$ years) and was more frequent in patients with continuous disease course (61). Previously, it has been indicated that the presence of the proline allele and its homozygous genotype is associated with the risk of ulcerative colitis (Pro allele: OR, 7.8; Pro/Pro: OR, 35.2) and primary open-angle glaucoma (Pro allele: OR, 2.1; Pro/Pro: OR, 3.9) in Iranian subjects $(50,62)$. In the Kuwaiti population, CAD prevalence exhibited an association with type 2 diabetes and high levels of triglyceride and cholesterol; however, there was no evidence of any influence of TP53 codon 72 genotypes (31). In Brazilian symptomatic CAD patients, neither atherosclerosis nor the risk factors were associated with Arg72Pro genotypes (63). Contrary with the current findings, Khan et al (35) reported Arg72 allele as a risk factor for CAD in South African (Indian 
ancestry) patients, but in line with the present study, the laboratory markers did not correlate with the genotypes. Similarly, the Arg72 variant has been associated with increased risk of CAD (OR=2.0) in Chilean patients (64).

A study by Manfredi et al (33), in agreement with Alkhalaf et al (31) and Lagares et al (63), failed to establish any association between Arg72Pro SNP and CAD in Italian subjects, but identified a significant association between CAD and smoking, dyslipidemia, type 2 diabetes, hypertension and family history of the disease. In a meta-analysis of 12 genetic variants related to CAD, including 2,473 subjects from Italy, Chile, Kuwait, and Europe, there was no significant association between TP53 rs1042522 and susceptibility to coronary disease (65). It is thus noteworthy that racial/ethnic differences appear to influence the association between Arg72Pro variants and CAD.

Furthermore, according to reported associations between TP53 and CAD, it appears that the overall incidence of CVD is higher in individuals with autoimmune disorders. This topic has been widely studied in patients with systemic lupus erythematosus and rheumatoid arthritis $(66,67)$. Furthermore, TP53 also serves a role in autoimmune inflammation, and this may explain the link between the gene and developing CAD (32) Protein tyrosine phosphatase, non-receptor type 22 (PTPN22) is among the known genes involved in autoimmune diseases including type 1 diabetes, celiac disease, rheumatoid arthritis and systemic lupus erythematosus $(68,69)$. In this regard, accompaniment of a common SNP of PTPN22 (tryptophan 620 allele) and the TP53 Pro allele has been reported to be associated with atherosclerosis by Saccucci et al (44).

The underlying environmental risk factors also serve a significant role in CAD. Obesity is a considerable health issue, associated with CVD, hypertension, diabetes, dyslipidemia and cancer $(70,71)$. Data suggest that the two northern provinces of Iran, Mazandaran and Guilan, have the highest BMI values among 31 provinces (72). An investigation in 440 women in Rasht (Guilan province) revealed that almost 24.8 and $2.9 \%$ of 440 participated women were overweight (BMI, >25) and obese (BMI, >30), respectively (73). Mahdavi Shahri et al (74), of a cohort of 500 elderly subjects, reported $47 \%$ as overweight, $38 \%$ as having hypertension, $30.4 \%$ has having dyslipidemia, and $18.8 \%$ as smokers. In a 7 -year cohort study in Isfahan, the incidence of conventional risk factors of CVD in both sexes was as follows; hypertension, $22.5 \%$; type 2 diabetes, $10.4 \%$; overweight, $29.6 \%$; and hypertriglyceridemia, $30.9 \%$ (75). Mediterranean countries including Italy (76) and France $(77,78)$ have a reportedly lower prevalence of conventional CAD risk factors including diabetes and obesity than the Iranian population $(79,80)$; but in a community-based survey in Greece, the prevalence of diabetes, hypertension, hypercholesterolemia and smoking were 11.1, 27.2, 23.8, and $38.9 \%$, respectively; this may be due to reduced physical activity and lower consumption of the Mediterranean diet in recent decades (81). Furthermore, age is an independent risk factor for CAD (82). In the present study, the patients were older than non-CAD subjects. This finding is in line with observations that elderly subjects are more prone to CAD (83).

The present study has some limitations that should be addressed. Other SNPs associated with obesity, diabetes, and hypertension were not examined; however determining their joint presence may have aided to clarify the role of genetic variants in CAD and the associated risk factors. Since genetic background influences the risk of CAD and response to treatment (84), evaluating the association between TP53 rs1042522 and CAD requires further investigation. This may aid to predict susceptibility to disease and to choose strategies for non-invasive screening. As the increase in life expectancy has caused CAD to become a notable health concern among the elderly, as also observed in the present study, another benefit of screening may be indication for lifestyle modification from an earlier age.

In conclusion, the present findings suggest that TP53 Arg/Pro polymorphism severs as a risk factor for CAD in patients from Northern Iran. However, no associations were identified between genotypes and clinical characteristics.

\section{Acknowledgements}

Not applicable.

\section{Funding}

The present study was supported by a grant from Mazandaran University of Medical Science, Sari, Iran (grant no. 2817).

\section{Availability of data and materials}

All data generated and/or analyzed during this study are included in this published article.

\section{Authors' contributions}

AHO was responsible for the conception and design of the project. RJ and VM were responsible for patient selection and sample collection. VON and OA performed the experiments. RAN analyzed and interpreted data. GJ and AM wrote the manuscript. GR critically revised the manuscript.

\section{Ethics approval and consent to participate}

Written informed consent agreeing to study participation following full disclosure of the protocol was obtained from all participants. The study was approved by the Ethics Committee of Mazandaran University of Medical Sciences, Sari, Iran (approval no. IR.MAZUMS.REC 96.2817).

\section{Consent for publication}

All participants in the present study signed written informed consent agreeing to the publication of clinical data following anonymization of personal information.

\section{Competing interests}

The authors declare that they have no competing interests regarding the publication of this paper.

\section{References}

1. Hedayatizadeh-Omran A,Rafiei A,KhajaviR,Alizadeh-Navaei R, Mokhberi V and Moradzadeh K: Association between ghrelin gene (Leu72Met) polymorphism and ghrelin serum level with coronary artery diseases. DNA Cell Biol 33: 95-101, 2014. 
2. Safdari R, Maleki M and Ghorbani V: Comparison of Cardiovascular Diseases Classification in some developed countries with Iran. Payavard Salamat. 3: 50-56, 2009.

3. Kounis NG, Soufras GD, Tsigkas G and Hahalis G: White blood cell counts, leukocyte ratios, and eosinophils as inflammatory markers in patients with coronary artery disease. Clin Appl Thromb Hemost 21: 139-143, 2015.

4. Nasehi MM, Moosazadeh M, Âmiresmaeili M, Parsaee M, Zakizadeh R and Mirzajani M: Prevalence of five main risk factors of non-communicable diseases in mazandaran province: A population based study. J Mazandaran Univ Med Sci 21: 193-202, 2012

5. Boutayeb A: The double burden of communicable and non-communicable diseases in developing countries. Trans $\mathrm{R}$ Soc Trop Med Hyg 100: 191-199, 2006.

6. Kolahdoozan S, Sadjadi A, Radmard AR and Khademi H: Five common cancers in Iran. Arch Iran Med 13: 143-146, 2010.

7. Naghavi M, Abolhassani F, Pourmalek F, Jafari N, Moradi Lakeh M, Eshrati B, Mahdavi Hezaveh N, Kazemeini H, Tehrani Banihashemi A and Shoaee SH: The burden of disease and injury in Iran in the year 2003. Iranian J Epidemiol 4: 1-19, 2008.

8. World Health Organization: Noncommunicable diseases (NCD) country profiles, 2014. http://www.who.int/nmh/countries/irn en.pdf?ua $=1$.

9. Hedayatizadeh-Omran A, Rafiei A, Alizadeh-Navaei R, Tehrani M Valadan R, Moradzadeh K, Panbechi M and Taghavi SM: Role of HER 2 in brain metastasis of breast cancer: A systematic review and meta-analysis. Asian Pac J Cancer Prev 16: 1431-1434, 2015

10. Rasouli M, Mohseni Kiasari A, Mokhberi V, Bagheri B, Daneshpour NS, Shariati R, et al: Global risk assessment of coronary heart disease using Framingham's scores for major risk factors. Majallah-i Danishgah-i Ulum-i Pizishki-i Mazandaran 15: 49-62, 2006.

11. Hatmi ZN, Tahvildari S, Gafarzadeh Motlag A and Sabouri Kashani A: Prevalence of coronary artery disease risk factors in Iran: A population based survey. BMC Cardiovase Disord 7: 32, 2007 .

12. Mafi Golchin M, Ghaderian SMH, Akhavan-Niaki H, Jalalian R, Heidari L and Salami SA: Analysis of two CDKN2B-AS polymorphisms in relation to coronary artery disease patients in north of Iran. Int J Mol Cell Med 6: 31-37, 2017.

13. den Hoed M, Strawbridge RJ, Almgren P, Gustafsson S, Axelsson T, Engström G, de Faire U, Hedblad B, Humphries SE, Lindgren CM, et al: GWAS-identified loci for coronary heart disease are associated with intima-media thickness and plaque presence at the carotid artery bulb. Atherosclerosis 239: 304-310, 2015.

14. Bergamaschi D, Gasco M, Hiller L, Sullivan A, Syed N, Trigiante G, Yulug I, Merlano M, Numico G, Comino A, et al: p53 polymorphism influences response in cancer chemotherapy via modulation of p73-dependent apoptosis. Cancer Cell 3: 387-402, 2003

15. Kung CP, Leu JI, Basu S, Khaku S, Anokye-Danso F, Liu Q, George DL, Ahima RS and Murphy ME: The P72R polymorphism of $\mathrm{p} 53$ predisposes to obesity and metabolic dysfunction. Cell Reports 14: 2413-2425, 2016.

16. Kawashima H, Takatori H, Suzuki K, Iwata A, Yokota M, Suto A Minamino T, Hirose K and Nakajima H: Tumor suppressor p53 inhibits systemic autoimmune diseases by inducing regulatory T cells. J Immunol 191: 3614-3623, 2013.

17. Chung WC, Lee KM, Lee BI, Chun JS, Lee SY, Chang UI, Park SH, Yang JM, Choi KY and Chung IS: P53 genetic polymorphism of gastric cancer in Korea. Korean J Intern Med (Korean Assoc Intern Med) 21: 28-32, 2006.

18. Kumar V, Abbas AK and Aster JC: Robbins and Cotran Pathologic Basis of Disease. 9th edition. Elsevier, New York, NY, 2015 .

19. Naccarati A, Polakova V, Pardini B, Vodickova L, Hemminki K, Kumar R and Vodicka P: Mutations and polymorphisms in TP53 gene - an overview on the role in colorectal cancer. Mutagenesis 27 211-218, 2012.

20. McGraw KL, Cluzeau T, Sallman DA, Basiorka AA, Irvine BA, Zhang L, Epling-Burnette PK, Rollison DE, Mallo M, Sokol L, et al: TP53 and MDM2 single nucleotide polymorphisms influence survival in non-del $(5 \mathrm{q})$ myelodysplastic syndromes. Oncotarget 6: 34437-34445, 2015.

21. Doosti A, Ghasemi Dehkordi P, Zamani M, Taheri S, Banitalebi $\mathrm{M}$ and Mahmoudzadeh M: Association of the p53 codon 72 polymorphism with colorectal cancer in South West of Iran. Sci Res Essays 6: 10.5897, 2011
22. Kung CP and Murphy ME: The role of the p53 tumor suppressor in metabolism and diabetes. J Endocrinol 231: R61-R75, 2016.

23. Liu DP, Song $\mathrm{H}$ and $\mathrm{Xu} \mathrm{Y:} \mathrm{A} \mathrm{common} \mathrm{gain} \mathrm{of} \mathrm{function} \mathrm{of} \mathrm{p53}$ cancer mutants in inducing genetic instability. Oncogene 29: 949-956, 2010

24. Najjar Sadeghi R, Azimzadeh P, Vahedi M, Mirsattari D, Molaei M, Mohebbi S, et al: Profile and frequency of p53 gene alterations in gastritis lesions from Iran 2010. pp65-75.

25. Soleimani A, Rahmani Y, Farshchian N, Delpisheh A, Khassi K, Shahmohammadi A and Amirifard N: The Evaluation of p53 polymorphism at codon 72 and association with breast cancer in Iran: A systematic review and meta-analysis. J Cancer Prev 21: 288-293, 2016.

26. Tang W, Zhou X, Nie S, Yang Z, Zhu H, Wu X, Zhao R and Luo Y: Association of p53 Arg72Pro polymorphism with gastric cancer: A meta-analysis. Biomarkers 17: 597-603, 2012.

27. Kankova K: Association of the Arg72Pro polymorphism in p53 with progression of diabetic nephropathy in T2DM subjects. J Nephrol Ther 4: 153, 2014.

28. Xu Y, Yao L, Ouyang T, Li J, Wang T, Fan Z, Lin B, Lu Y and Xie Y: p53 codon 72 polymorphism predicts the pathologic response to neoadjuvant chemotherapy in patients with breast cancer. Clin Cancer Res 11: 7328-7333, 2005.

29. Vikhanskaya F, Siddique MM, Kei Lee M, Broggini M and Sabapathy K: Evaluation of the combined effect of p53 codon 72 polymorphism and hotspot mutations in response to anticancer drugs. Clin Cancer Res 11: 4348-4356, 2005.

30. Frank AK, Leu JI, Zhou Y, Devarajan K, Nedelko T, Klein-Szanto A, Hollstein M and Murphy ME: The codon 72 polymorphism of p53 regulates interaction with NF- $\{$ kappa\}B and transactivation of genes involved in immunity and inflammation. Mol Cell Biol 31: 1201-1213, 2011.

31. Alkhalaf M, Al-Bustan S, Hamoda $\mathrm{H}$ and Abdella $\mathrm{N}$ : Polymorphism of p53 gene codon 72 in Kuwaiti with coronary artery disease and diabetes. Int J Cardiol 115: 1-6, 2007.

32. Gloria-Bottini F, Banci M, Saccucci P, Neri A, Bottini E and Magrini A: p53 codon 72 polymorphism and coronary artery disease: Evidence of interaction with $\mathrm{ACP}_{1}$. Med Sci Monit 18 : CR712-CR715, 2012.

33. Manfredi S, Masetti S, Botto N, Colombo MG, Terrazzi M, Vassalle C, Biagini A and Andreassi MG: P53 codon 72 polymorphism in coronary artery disease: No evidence for association with increased risk or micronucleus frequency. Environ Mol Mutagen 40: 110-115, 2002.

34. Judkins MP: Selective coronary arteriography. I. A percutaneous transfemoral technic. Radiology 89: 815-824, 1967.

35. Khan S, Phulukdaree A, Ramkaran P, Moodley D and Chuturgoon AA: The Arg72 variant of the p53 functional polymorphism (rs1042522) is associated with coronary artery disease in young South Africans of Indian ancestry. Gene 593: 261-264, 2016.

36. Ara S, Lee PS, Hansen MF and Saya H: Codon 72 polymorphism of the TP53 gene. Nucleic Acids Res 18: 4961, 1990.

37. Morris JA and Gardner MJ: Calculating confidence intervals for relative risks (odds ratios) and standardised ratios and rates. $\mathrm{Br}$ Med J (Clin Res Ed) 296: 1313-1316, 1988.

38. Sikka S and Sikka P: Association of human papilloma virus 16 infection and p53 polymorphism among tobacco using oral leukoplakia patients: A clinicopathologic and genotypic study. Int J Prev Med 5: 430-438, 2014

39. Sadeghi M, Haghdoost AA, Bahrampour A and Dehghani M: Modeling the burden of cardiovascular diseases in Iran from 2005 to 2025: The impact of demographic changes. Iran J Public Health 46: 506-516, 2017

40. Maracy MR, Isfahani MT, Kelishadi R, Ghasemian A, Sharifi F, Shabani R, Djalalinia S, Majidi S, Ansari H, Asayesh H, et al: Burden of ischemic heart diseases in Iran, 1990-2010: Findings from the global burden of disease study 2010. J Res Med Sci 20: 1077-1083, 2015.

41. Ebrahimi M, Kazemi-Bajestani SM, Ghayour-Mobarhan M and Ferns GA: Coronary artery disease and its risk factors status in Iran: A review. Iran Red Crescent Med J 13: 610-623, 2011.

42. Hirashiki A, Yamada Y, Murase Y, Suzuki Y, Kataoka H, Morimoto Y, Tajika T, Murohara T and Yokota M: Association of gene polymorphisms with coronary artery disease in low- or high-risk subjects defined by conventional risk factors. J Am Coll Cardiol 42: 1429-1437, 2003.

43. Satti HS, Hussain S and Javed Q: Association of interleukin-6 gene promoter polymorphism with coronary artery disease in Pakistani families. ScientificWorldJournal 2013: 538365, 2013. 
44. Saccucci P, Banci M, Amante A, Bottini E and Gloria-Bottini F: Coronary artery disease: Evidence of interaction between PTPN22 and p53 genetic polymorphisms. Cardiology 120 166-168, 2011

45. Gu J, Spitz MR, Zhao H, Lin J, Grossman HB, Dinney CP and $\mathrm{Wu} \mathrm{X}$ : Roles of tumor suppressor and telomere maintenance genes in cancer and aging - an epidemiological study. Carcinogenesis 26: 1741-1747, 2005.

46. Grizzi F and Chiriva-Internati M: Cancer: Looking for simplicity and finding complexity. Cancer Cell Int 6: 4, 2006.

47. Dastjerdi MN, Hasanzadeh M, Talebi A and Akbari M: Investigation of $\mathrm{p} 53$ codon 72 polymorphism in patients with nonmelanoma skin cancers in Isfahan. Majallah-i Danishkadah-i Pizishki-i Isfahan 29: 679-685, 2011.

48. Malekzadeh R, Bishehsari F, Mahdavinia M and Ansari R: Epidemiology and molecular genetics of colorectal cancer in Iran: A review. Arch Iran Med 12: 161-169, 2009.

49. Bonafé M, Ceccarelli C, Farabegoli F, Santini D, Taffurelli M, Barbi C, Marzi E, Trapassi C, Storci G, Olivieri F, et al: Retention of the p53 codon 72 arginine allele is associated with a reduction of disease-free and overall survival in arginine/proline heterozygous breast cancer patients. Clin Cancer Res 9: 4860-4864, 2003

50. Neamatzadeh H, Soleimanizad R, Atefi A, Zare-Shehneh M, Gharibi S, Shekari A and Rahimzadeh AB: Association between p53 codon 72 (Arg72Pro) polymorphism and primary open-angle glaucoma in Iranian patients. Iran Biomed J 19: 51-56, 2015.

51. Moradi MT, Salehi Z, Aminian K and Yazdanbod A: Effects of p53 codon 72 and MDM2 SNP309 polymorphisms on gastric cancer risk among the Iranian population. Asian Pac J Cancer Prev 15: 7413-7417, 2014

52. Hedayatizadeh-Omran A, Alizadeh-Navaei R, Janbabaei G, Omrani-Nava V, Hasheminasab Y, Amjadi O and Tehrani M: Association of P53 gene polymorphism with gastric cancer in Northern Iran as a high-risk region. Biomed Rep 8: 433-438, 2018.

53. MojtahediZ,HashemiSB,KhademiB, Karimi M,Haghshenas MR, Fattahi MJ and Ghaderi A: p53 codon 72 polymorphism association with head and neck squamous cell carcinoma. Rev Bras Otorrinolaringol (Engl Ed) 76: 316-320, 2010.

54. Sina M, Pedram M, Ghojazadeh M, Kochaki A and Aghbali A P53 gene codon 72 polymorphism in patients with oral squamous cell carcinoma in the population of northern Iran. Med Oral Pato Oral Cir Bucal 19: e550-e555, 2014.

55. Gerayli S, Pasdar A, Rostami S, Sepahi S, Mousalreza Hoseini S, Jahanian R, Gholoobi A, Meshkat Z and Ahadi M: Association of codon 72 of p53 gene polymorphism with chronic hepatitis $C$ virus infection: A case control study. J Cell Mol Res 8: 46-51, 2016.

56. Huxley RR, Ansary-Moghaddam A, Clifton P, Czernichow S Parr CL and Woodward M: The impact of dietary and lifestyle risk factors on risk of colorectal cancer: A quantitative overview of the epidemiological evidence. Int J Cancer 125: 171-180, 2009.

57. Ahmad A, Banerjee S, Wang Z, Kong D, Majumdar AP and Sarkar FH: Aging and inflammation: Etiological culprits of cancer. Curr Aging Sci 2: 174-186, 2009.

58. Lopez-Candales A,HernándezBurgos PM,Hernandez-Suarez DF and Harris D: Linking chronic inflammation with cardiovascular disease: From normal aging to the metabolic syndrome. J Nat Sci 3: e341, 2017

59. Gloria-Bottini F, Banci M, Saccucci P, Nardi P, Scognamiglio M, Papetti F, Magrini A, Pellegrino A, Bottini E and Chiariello L: p53 codon 72 polymorphism and coronary artery disease: Evidence of association with left ventricular ejection fraction. Am J Med Sci 343: 127-130, 2012.

60. Khodadadi A, Mir Shafeie A, Eslami MB, Razavi A and Hekmat K: An investigation upon the effectiveness of LVA-7220 as an immunomodulator on chronic ulcerative colities in rats. Koomesh 4: 151-157, 2003

61. Vietri MT, Riegler G, Ursillo A, Caserta L, Cioffi M and Molinari AM: p53 codon 72 polymorphism in patients affected with ulcerative colitis. J Gastroenterol 42: 456-460, 2007.

62. Vaji S, Salehi Z and Aminian K: Association of p53 codon 72 genetic polymorphism with the risk of ulcerative colitis in northern Iran. Int J Colorectal Dis 26: 235-238, 2011.

63. Lagares MH, Silva KSF, Barbosa AM, Rodrigues DA, Costa IR, Martins JVM, Morais MP, Campedelli FL and Moura KKVO Analysis of p53 gene polymorphism (codon 72) in symptomatic patients with atherosclerosis. Genet Mol Res 16: 1-9, 2017.
64. Caamaño J, Saavedra N, Jaramillo PC, Lanas C, Lanas F and Salazar LA: TP53 codon 72 polymorphism is associated with coronary artery disease in Chilean subjects. Med Princ Pract 20: 171-176, 2011.

65. Ye H, Li X, Wang L, Liao Q, Xu L, Huang Y, Xu L, Xu X, Chen C, $\mathrm{Wu} \mathrm{H}$, et al: Genetic associations with coronary heart disease: Meta-analyses of 12 candidate genetic variants. Gene 531: 71-77, 2013.

66. Frostegård $\mathrm{J}$ : Atherosclerosis in patients with autoimmune disorders. Arterioscler Thromb Vasc Biol 25: 1776-1785, 2005.

67. Renjith AS, Marwaha V, Aggarwal N, Koshy V, Singal VK and Kumar KVSH: Prevalence of left ventricular dysfunction in rheumatoid arthritis. J Family Med Prim Care 6: 622-626, 2017.

68. Ostanek L, Ostanek-Pańka M, Bobrowska-Snarska D, Bińczak-Kuleta A, Fischer K, Kaczmarczyk M, Ciechanowicz A and Brzosko M: PTPN22 1858C $>$ T gene polymorphism in patients with SLE: Association with serological and clinical results. Mol Biol Rep 41: 6195-6200, 2014.

69. Abbasi Z, Kazemi Nezhad SR, Pourmahdi-Broojeni M and Rajaei E: Association of PTPN22 rs2476601 Polymorphism with rheumatoid arthritis and celiac disease in Khuzestan province, southwestern Iran. Iran Biomed J 21: 61-66, 2017.

70. Jafari-Adli S, Jouyandeh Z, Qorbani M, Soroush A, Larijani B and Hasani-Ranjbar S: Prevalence of obesity and overweight in adults and children in Iran; a systematic review. J Diabetes Metab Disord 13: 121, 2014

71. Davoodi SH, Malek-Shahabi T, Malekshahi-Moghadam A, Shahbazi R and Esmaeili S: Obesity as an important risk factor for certain types of cancer. Iran J Cancer Prev 6: 186-194, 2013.

72. Ahmadi A, Mobasheri M and Soori H: Prevalence of major coronary heart disease risk factors in Iran. Int J Epidemiol Res 1: 3-8, 2014

73. Monfared AB, Hatami $\mathrm{H}$ and Isabeiglou H: Prevalence and associated factors of overweight and obesity in reproductive-aged women in Rasht. J Health Field 4: 39-46, 2016.

74. Mahdavi Shahri SM, Khalili Z, Sadrollahi A and Saadati B: Prevalence of risk factors for cardiovascular disease among elderly people in Kashan city, Iran, 2014. Cardiovasc Nurs J 3: 6-13, 2014.

75. Sadeghi M, Talaei M, Oveisgharan S, Rabiei K, Dianatkhah M, Bahonar A and Sarrafzadegan N: The cumulative incidence of conventional risk factors of cardiovascular disease and their population attributable risk in an Iranian population: The Isfahan Cohort Study. Adv Biomed Res 3: 242, 2014.

76. Italian National Institute of Statistics: Diabetes in Italy (2000-2016). https://www.istat.it/it/files//2017/07/Report Diabetes_En_def.pdf.

77. Eschwege E, Basdevant A, Crine A, Moisan C and Charles MA: Type 2 diabetes mellitus in France in 2012: Results from the ObEpi survey. Diabetes Metab 41: 55-61, 2015.

78. Obesity and the Economics of Prevention: Fit not Fat - France Key Facts. http://www.oecd.org/els/health-systems/obesityandtheeconomicsofpreventionfitnotfat-francekeyfacts.htm.

79. Rahmani A, Sayehmiri K, Asadollahi K, Sarokhani D, Islami F and Sarokhani M: Investigation of the prevalence of obesity in Iran: A systematic review and meta-analysis study. Acta Med Iran 53: 596-607, 2015.

80. Esteghamati A, Larijani B, Aghajani MH, Ghaemi F, Kermanchi J, Shahrami A, Saadat M, Esfahani EN, Ganji M, Noshad S, et al: Diabetes in Iran: Prospective analysis from first nationwide diabetes report of National Program for Prevention and Control of Diabetes (NPPCD-2016). Sci Rep 7: 13461, 2017.

81. Gikas A, Lambadiari V, Sotiropoulos A, Panagiotakos D and Pappas S: Prevalence of major cardiovascular risk factors and coronary heart disease in a sample of Greek adults: The saronikos study. Open Cardiovasc Med J 10: 69-80, 2016.

82. Dhingra R and Vasan RS: Age as a risk factor. Med Clin North Am 96: 87-91, 2012.

83. Jackson CF and Wenger NK: Cardiovascular disease in the elderly. Rev Esp Cardiol 64: 697-712, 2011.

84. Yang HH, Chen Y and Gao CY: Associations of P2Y12R gene polymorphisms with susceptibility to coronary heart disease and clinical efficacy of antiplatelet treatment with clopidogrel. Cardiovasc Ther 34: 460-467, 2016. 